\title{
Tracking of gross motor coordination in Portuguese children
}

Rafael S. Henrique, Alcibíades V. Bustamante, Duarte L. Freitas, Go Tani, Peter T. Katzmarzyk \& José A. Maia

To cite this article: Rafael S. Henrique, Alcibíades V. Bustamante, Duarte L. Freitas, Go Tani, Peter T. Katzmarzyk \& José A. Maia (2018) Tracking of gross motor coordination in Portuguese children, Journal of Sports Sciences, 36:2, 220-228, DOI: 10.1080/02640414.2017.1297534

To link to this article: https://doi.org/10.1080/02640414.2017.1297534

册 Published online: 01 Mar 2017.

Submit your article to this journal

Шll Article views: 345

Q View related articles $ک$

View Crossmark data

Citing articles: 9 View citing articles $\sqsubset$ 


\title{
Tracking of gross motor coordination in Portuguese children
}

\author{
Rafael S. Henriquea ${ }^{a}$ Alcibíades V. Bustamante ${ }^{b}$, Duarte L. Freitasc ${ }^{c}$, Go Tani ${ }^{d}$, Peter T. Katzmarzyk ${ }^{e}$ and José A. Maia ${ }^{f}$ \\ ${ }^{a}$ Higher School of Physical Education, University of Pernambuco, Recife, Brazil; ${ }^{b}$ Academic Department of Applied Sciences for Physical Education \\ and Sport, National University of Education Enrique Guzmán y Valle, Lima, Peru; 'Department of Physical Education and Sport, University of

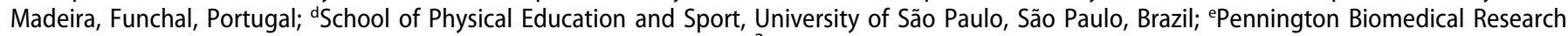 \\ Center, Louisiana State University, Baton Rouge, Louisiana, USA; ${ }^{\mathrm{f}} \mathrm{CIFI}{ }^{2} \mathrm{D}$, Faculty of Sport, Kinanthropometry Lab, University of Porto, Porto, \\ Portugal
}

\begin{abstract}
The purpose of this study was to investigate the tracking of gross motor coordination (GMC) and to profile children at 6 years of age who consistently showed higher stability patterns in different levels of GMC. The participants were 245 children (123 boys and 122 girls) who were assessed longitudinally from 6 to 9 years of age. GMC was assessed using the Korperkoordinationtest fur Kinder (KTK) test battery. Anthropometry, physical activity, and health- and performance-related physical fitness were also measured. Cohen's kappa $(\kappa)$ was used to estimate tracking. Tracking was poor for all GMC tests $(0.17 \leq \kappa \leq 0.38)$ and moderate for the GMC motor quotient (MQ) in both boys and girls $(0.44 \leq \kappa \leq 0.45)$. Instability at the extremes was low in GMC tests and negligible for MQ. Children who consistently showed high GMC levels during the 4 years of follow-up were lighter, had lower body mass index and subcutaneous fat, and showed higher scores in physical fitness tests at 6 years of age than those who consistently had low GMC levels. In conclusion, GMC showed low-to-moderate tracking over time in childhood. However, children who consistently demonstrated high GMC levels over time had healthier profiles at 6 years of age.
\end{abstract}

ARTICLE HISTORY Accepted 10 February 2017

KEYWORDS

Tracking; gross motor coordination; longitudinal studies; children

\section{Introduction}

There is a growing evidence linking gross motor coordination (GMC) to healthy traits such as physical activity (Lopes, Rodrigues, Maia, \& Malina, 2011; Souza et al., 2014), physical fitness (Fransen et al., 2014; Souza et al., 2014) and weight status/adiposity (Lopes, Stodden, Bianchi, Maia, \& Rodrigues, 2012; Antunes et al., 2015).

Although longitudinal changes in GMC have been investigated during childhood and adolescence (e.g., Ahnert, Schneider, \& Bös, 2009; Antunes et al., 2016; Deus et al., 2008; Willimczik, 1980), very few studies have examined how GMC tracks across time, i.e., the degree to which a child tends to keep her/his relative rank position within her/his group over time (Kowalski \& Schneiderman, 1992). Overall, existing autocorrelation data in children and adolescents suggest that GMC tracks moderately to high ( $r$ between 0.76 and 0.84 ) for the motor quotient (MQ) and overall indicators of GMC (Ahnert et al., 2009), and low to moderately high ( $r$ between 0.15 and 0.74) for specific GMC tests (Antunes et al., 2016; Deus et al., 2008; Willimczik, 1980).

The above-mentioned tracking studies relied on auto-correlations to express the idea of GMC stability. Notwithstanding the relevance of this statistical approach, it suffers from a number of shortcomings: (1) the lack of precise knowledge about the characteristics and magnitude of inter-individual differences in intra-individual change; (2) difficulty in summarising auto-correlations when more than two time points are present; (3) difficulty in interpreting the magnitude of autocorrelations, and classify tracking beyond Malina's (2001) subjective cut-off and (4) the likelihood of obtaining higher stability values in short follow-up periods (Malina, 2001; Twisk, 2003; Twisk, Kemper, \& Mellenbergh, 1994). Furthermore, tracking can be variously conceived and analysed (Kowalski \& Schneiderman, 1992; Souza et al., 2016) which poses problems when trying to interpret and compare tracking values given its elusive definition and use (Maia et al., 2001; Twisk, 2003).

The idea of "canalisation" was first proposed by Waddington $(1942,1957)$ in the biological context to describe developmental pathways and mechanisms against influences or environmental perturbations during development. Later, Tanner (1978) extended the notion of developmental canals to human physical growth, namely height, especially to monitor the stability of patterns over time. In this study, we will explore the suggestions of Berenson et al. (1978) and Clarke, Schrott, Leaverton, Connor, and Lauer (1978) about the probability of an individual to remain in the same quantile of the distribution over time, as well as the recommendations of Ware and Wu (1981) of using the kappa statistic (Cohen, 1960 ) in order to provide a chance-corrected measure of concordance for quantile membership. Such tools will allow us to provide further insights into the investigation of GMC tracking, particularly the identification of children with stable (withinsubject consistently in high or low GMC performance canals) 
or unstable (within-subject inconsistency, i.e., "moving" up and down across GMC canals) trajectories.

Additionally, the identification of the multivariate health profile of children in early childhood may enable the identification of more effective strategies for both GMC development and the factors associated with it. Although longitudinal data may indicate that higher levels of GMC protect against decreases in physical activity levels (Lopes et al., 2011) and physical fitness (Fransen et al., 2014), as well as unhealthy weight development throughout childhood (Rodrigues et al., 2016), the identification of that profile has been poorly explored in the literature.

Therefore, our aims are (1) to investigate GMC tracking in children followed longitudinally from 6 to 9 years of age using the concept of GMC canals and Cohen's $k$ as a suitable statistic, (2) to identify positive and negative GMC instability when children systematically cross over their canals and (3) to move "back in time" and profile the children at 6 years of age who showed a consistent stability pattern from 6 to 9 years of age. Consistent with the previous reports, we hypothesise that GMC tracks moderately, yet we also speculate that positive and negative trajectories of instability will show different profiles for GMC, and that children who are consistently more coordinated from 6 to 10 years of age show healthier profiles already at 6 years compared to less coordinated children.

\section{Methods}

\section{Sample}

Data for this study are from a mixed-longitudinal study carried out in Azorean children, Portugal. Participants lived in four main Azores islands: Faial, Pico, São Miguel and Terceira; these (islands) represent $\sim 99 \%$ of the total population of school children/adolescents in the nine Azores islands. Four cohorts, with about 300 children each, were followed for 4-5 consecutive years (6-10 years, 10-13 years, 13-16 years and 16-19 years, respectively). The present study will only deal with children from the first cohort (decimal ages of 6.469.46 years). A total of 245 children (123 boys and 122 girls) remained in the study and were used in the current study. Independent samples t-tests were carried out across a wide range of variables (anthropometry, GMC, physical activity, health- and performance-related physical fitness) with the intention of exploring differences between completers and dropouts. Only two statistically significant differences were found for hopping for height on one foot and standing long jump. Written informed consent was obtained from parents or legal guardians, and the study was approved by the ethics committee of the Faculty of Sport, University of Porto.

\section{Anthropometry}

Stature was measured having the children's head in the Frankfurt plane with a stadiometer (Siber Hegner, Switzerland) to the nearest $0.1 \mathrm{~cm}$. Body mass was measured with children wearing light clothing and without shoes on a Seca scale (Seca Optima 760, Germany) to the nearest $0.1 \mathrm{~kg}$. Body mass index (BMI) was calculated (weight $(\mathrm{kg}) / \mathrm{height}$ $\left.\left(\mathrm{m}^{2}\right)\right)$ and children were classified as normal weight, overweight and obese according to sex and age-specific BMI cutoff values (Cole, Bellizzi, Flegal, \& Dietz, 2000). Triceps and subscapular skinfolds were measured on the right side of the body to the nearest $0.1 \mathrm{~mm}$, following the procedures of Lohman, Roche, and Martorell (1988). Skinfolds were measured in duplicate by the same technician with a Holtain skinfold caliper (Holtain, UK). The sum of triceps and subscapular skinfolds were calculated to provide an estimate of subcutaneous fat.

\section{Gross motor coordination}

GMC was assessed with the Korperkoordinationtest fur Kinder (KTK) test battery (Kiphard \& Schilling, 1974), which includes the following tests:

- Walking backwards (WB): the child walks backwards three times along each of three balance beams of decreasing width $(6.0,4.5$ and $3.0 \mathrm{~cm}$, respectively; $3 \mathrm{~m}$ length). The number of successful steps of a maximum of 24 steps (eight per trial) was counted for each balance beam.

- Jumping sideways (JS): the child makes consecutive jumps over a wooden slat $(60 \mathrm{~cm} \times 4 \mathrm{~cm} \times 2 \mathrm{~cm})$ as fast as possible in $15 \mathrm{~s}$. The number of jumps over two trials was summed.

- Hopping for height on one foot $(\mathrm{HH})$ : the child was oriented to hop on one foot over a foam square $(50 \mathrm{~cm}$ $\times 20 \mathrm{~cm} \times 5 \mathrm{~cm}$ ). After a successful hop with each foot, the height was increased by adding a square. Three, two or one point(s) were recorded for successful performance on the first, second or third trial, respectively. A maximum of 39 points (ground level +12 squares) could be scored for each leg, yielding a possible maximum score of 78 .

- Moving sideways (MS): the child begins standing with both feet on one platform $(25 \mathrm{~cm} \times 25 \mathrm{~cm} \times 2 \mathrm{~cm}$ supported on four legs $3.7 \mathrm{~cm}$ high) and holding a second identical platform in his/her hands; alongside the first and steps on to it; places the second platform alongside the first and stepping on it, and so on. For each successful transfer from one platform to the other, two points is given (one for shifting the platform and the other for transfer of the body). The number of points in $20 \mathrm{~s}$ was counted and summed over two trials.

The raw scores of each test were converted into standardised scores, adjusted for age and sex, using normative data tables in the KTK manual (Kiphard \& Schilling, 1974). The sum of standardised scores for each test provides the motor quotient (MQ), which expresses the overall score of GMC adjusted for age and sex.

\section{Physical activity}

Physical activity was assessed using the Godin-Shephard questionnaire (Godin \& Shephard, 1985), which was administered through a face-to-face interview. The child reported the 
number of times/week they spent at least $15 \mathrm{~min}$ in activities classified as mild ( 3 metabolic equivalents (MET s)), moderate (5 METs) or strenuous (9 METs). A total weekly score of arbitrary units was derived by multiplying the frequency of participation in each category of three intensity levels by the corresponding anticipated MET value associated with that category and summing the products $(3 \times$ number of times in light activities $+5 \times$ number of times in moderate activities + $9 \times$ number of times in strenuous activities) (Godin \& Shephard, 1985). Previous validation studies have reported moderate correlations ( $r$ between 0.40 and 0.62 ) when comparing the physical activity output of accelerometers and the Godin-Shephard questionnaire in children aged 7-10 years (Eisenmann, Milburn, Jacobsen, \& Moore, 2002 ; Scerpella, Tuladhar, \& Kanaley, 2002). This questionnaire was also used in Portuguese children (Chaves et al., 2015; Lopes, Monteiro, Barbosa, Magalhães, \& Maia, 2001).

\section{Physical fitness}

Components of health- and performance-related physical fitness were assessed with the Fitnessgram test battery (Welk \& Meredith, 2008) and AAHPER Youth Fitness Test (American Alliance for Health, Physical Education and Recreation, 1980).

Health-related physical fitness:

- 1-mile run/walk (aerobic capacity): the child ran or walked 1 mile $(1609 \mathrm{~m})$ in the shortest time possible.

- Push-ups (upper body strength and endurance): the child lowered their body to a $90^{\circ}$ elbow angle and performed as many repetitions as possible.

- Curl-ups (strength and endurance of abdominal muscles): the child lied down with knees bent and feet unanchored, and completed as many curl-ups as possible.

- Trunk lift (trunk extensor strength): the child lied face down and lifted the trunk as much as they could. The height of the trunk from the floor was recorded in centimetres.

Performance-related physical fitness:

- 50-yard (45.7 m) dash (speed): the child ran this distance as fast as possible.

- Standing long jump (explosive power): the child jumped as far as possible from a standing position.

- Handgrip strength (static strength): the child squeezed the dynamometer as vigorously as possible for 5-10 s.

- Shuttle-run (agility): the child ran as fast as possible between two parallel lines $9 \mathrm{~m}$ apart. Two small blocks of wood were placed behind one line; the child ran and picked up one block, ran back to the starting line, placed the block behind the line, and repeated the same task in retrieving the second block.

\section{Quality control}

All measures were taken annually during September and October by physical education teachers of each participating school who were previously trained and supervised by the principal investigator. The reliability was estimated via ANOVA-based intraclass correlation coefficients $(R)$, using a test-retest protocol. A sample of 25 children (13 boys) from each of the four islands was randomly selected. Estimated reliability $(R)$ ranged between 0.98 and 0.99 for stature and body mass, 0.72 and 0.99 for physical fitness tests, 0.75 and 0.91 for GMC and 0.75 for physical activity.

\section{Statistical analysis}

Exploratory analysis stratified by sex, within each assessment year, was firstly done to detect missing data, input errors and presence of outliers. Tracking analysis was done with the Longitudinal Data Analysis (LDA) software (Kowalski \& Schneiderman, 1992). Using a non-parametric approach and Cohen's $\kappa$, the basic idea was that "if tracking exists, we could expect that an individual's successive measurement of GMC will stay in the same quantile of the population distribution as it changes over time" (Kowalski \& Schneiderman, 1992, p. 34). As such, the sample of values at each time point was divided into tertiles, and a measure of concordance for tertile membership was computed. Based on Landis and Koch (1977), tracking was classified as follows: $\kappa>0.75$ excellent; $0.40 \leq \kappa \leq 0.75$ moderate; $\kappa<0.40$ poor. In the current investigation, three developmental canals were considered for each KTK test and MQ (upper canal: above percentile 66; middle canal: between percentiles 33 and 66; lower canal: below percentile 33). For each GMC test and for $M Q, k$ values of boys and girls were compared using a chi-square statistic (Schneiderman, Willis, Kowalski, \& Ten Have, 1992).

From GMC canals, the percentage of children's trajectories with stability or instability was computed. Despite the many possible trajectories $\left(81 ; 3^{4}\right.$ with three canals and four observations), our focus was on children with stability as well as instability at the extremes, i.e., from the first to the fourth observation. Stability within the upper canal was identified when a child consistently stayed in the third canal from 6 to 9 years (see Figure 1(a) for three possible examples), while stability within the lower canal refers to the opposite, i.e., when a child consistently remains in the first canal from 6 to 9 years (see Figure 1(b) for three possible examples). Positive instability was identified when a child was in the lower canal at 6 years and moved to the upper canal at 9 years (see Figure 1(c) for three possible examples); negative instability was recognised when a child was in the upper canal at 6 years, and moved to the lower canal at 9 years (see Figure 1(d) for three possible examples). The number and percentage of cases that followed these four possible trajectories was computed for each KTK test and $M Q$.

Based on MQ development of those children who consistently remained in the upper and lower canals over time, we moved "back in time", and profiled and contrasted them at 6 years of age in terms of physical activity, health- and performance-related physical fitness, as well as anthropometry and subcutaneous fat at baseline. Independent samples t-tests were used to compare differences between the groups 

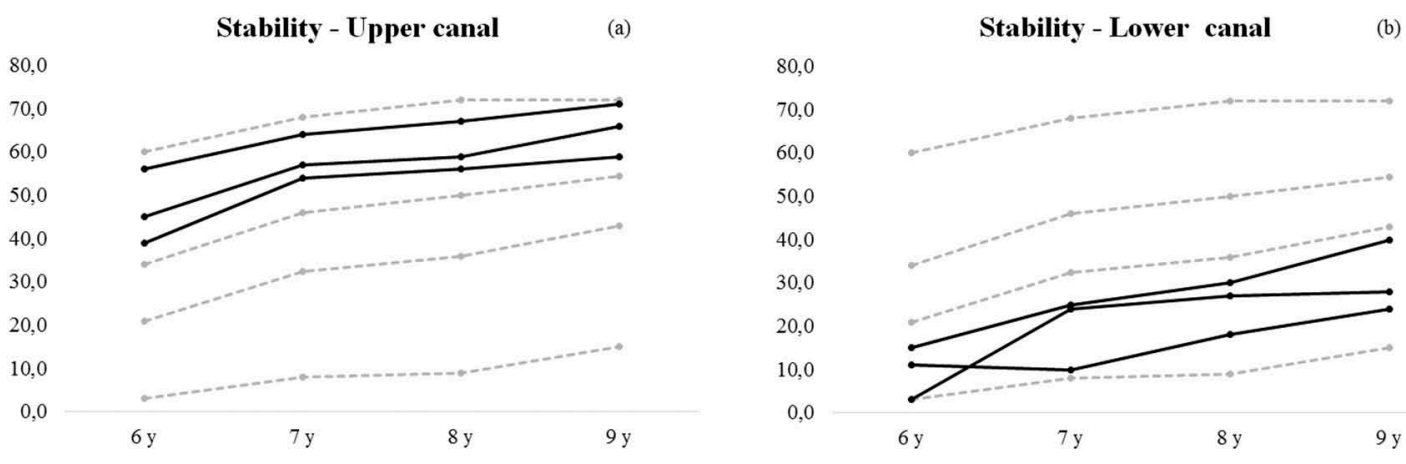

(b)

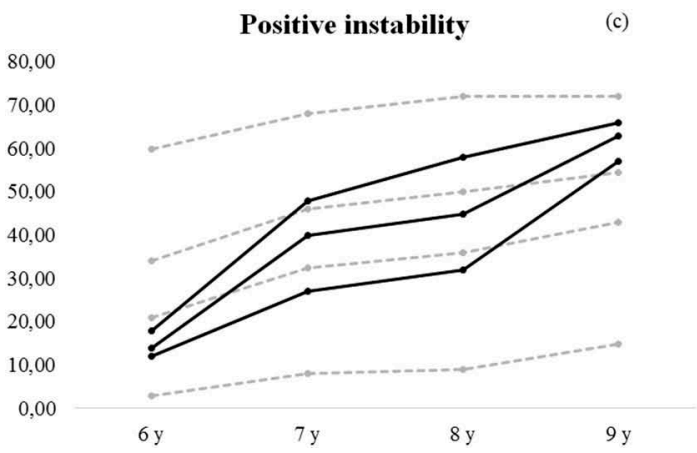

\section{0,00
70,00
60,00
50,00
40,00
30,00
20,00
10,00
0,00}

Negative instability

(d)

Figure 1. Possible examples of stability within the upper and lower canals, and positive and negative instability of GMC from 6 to 9 years of age of three children.

who consistently stayed in the upper and lower canals. This analysis was carried out using IBM SPSS 23.0 (IBM, 2015).

\section{Results}

Descriptive characteristics of the participants are presented in Table 1. Children become taller and heavier from 6 to 9 years of age, and BMl showed only a small mean change. An increase is observed for GMC and health- and performance-related physical fitness tests, whereas physical activity levels decrease over time.

Table 2 shows Cohen's $k$ tracking values for each GMC test and for boys and girls, separately. $k$ Values are poor across all tests, varying from $K=0.17(\mathrm{MS})$ to $K=0.36(\mathrm{HH})$ in girls, and from $K=0.18(\mathrm{MS})$ to $K=0.38(\mathrm{HH})$ in boys. The MQ demonstrated moderate $K$ values for both sexes ( $K=0.44$ and 0.45 for girls and boys, respectively). $k$ Values of boys and girls do not significantly differ (WB: $x^{2}=0.78, P>0.05 ; \mathrm{JS}: X^{2}=0.40$,

Table 1. Descriptive values (mean \pm SD) for girls $(n=122)$ and boys $(n=123)$ at each observation.

\begin{tabular}{|c|c|c|c|c|c|c|c|c|}
\hline \multirow[b]{2}{*}{ Tests } & \multicolumn{4}{|c|}{ Girls } & \multicolumn{4}{|c|}{ Boys } \\
\hline & 6 years & 7 years & 8 years & 9 years & 6 years & 7 years & 8 years & 9 years \\
\hline \multicolumn{9}{|l|}{ Anthropometry } \\
\hline Stature $(\mathrm{m})$ & $117.6 \pm 5.6$ & $122.6 \pm 5.9$ & $128.2 \pm 6.4$ & $133.2 \pm 6.5$ & $118.9 \pm 5.1$ & $123.9 \pm 5.5$ & $129.5 \pm 5.8$ & $134.5 \pm 6.3$ \\
\hline $\mathrm{BMI}\left(\mathrm{kg} \cdot \mathrm{m}^{-2}\right)$ & $17.3 \pm 2.4$ & $17.3 \pm 2.7$ & $18.0 \pm 2.9$ & $18.7 \pm 3.3$ & $17.3 \pm 2.6$ & $17.4 \pm 3.0$ & $17.9 \pm 3.3$ & $18.7 \pm 3.7$ \\
\hline Adiposity (sum of SF) & $19.3 \pm 8.6$ & $20.3 \pm 9.7$ & $22.9 \pm 9.7$ & $25.2 \pm 11.5$ & $16.4 \pm 8.8$ & $16.8 \pm 8.5$ & $18.6 \pm 10.4$ & $20.9 \pm 11.7$ \\
\hline \multicolumn{9}{|l|}{ Gross motor coordination } \\
\hline Walking backwards (points) & $28.6 \pm 15.5$ & $36.6 \pm 14.7$ & $40.5 \pm 11.5$ & $46.6 \pm 13.7$ & $29.0 \pm 13.8$ & $37.9 \pm 13.9$ & $43.3 \pm 13.7$ & $48.3 \pm 13.0$ \\
\hline Moving sideways (points) & $27.6 \pm 5.2$ & $35.7 \pm 6.5$ & $39.0 \pm 7.2$ & $40.4 \pm 6.9$ & $30.5 \pm 5.0$ & $36.9 \pm 6.5$ & $40.3 \pm 5.5$ & $41.9 \pm 7.6$ \\
\hline Motor quotient (points) & $81.7 \pm 14.3$ & $89.5 \pm 15.0$ & $92.9 \pm 16.6$ & $79.2 \pm 16.9$ & $94.9 \pm 13.9$ & $98.8 \pm 16.1$ & $97.0 \pm 16.3$ & $88.0 \pm 17.4$ \\
\hline \multicolumn{9}{|l|}{ Physical activity } \\
\hline Total physical activity & $41.2 \pm 32.9$ & $37.8 \pm 23.3$ & $34.8 \pm 31.3$ & $33.3 \pm 19.8$ & $51.4 \pm 31.8$ & $42.1 \pm 24.0$ & $47.7 \pm 22.8$ & $49.3 \pm 23.3$ \\
\hline \multicolumn{9}{|l|}{ Health-related physical fitness } \\
\hline 1-mile run/walk (min) & $14.2 \pm 2.7$ & $14.6 \pm 3.5$ & $14.3 \pm 3.1$ & $13.7 \pm 2.4$ & $13.1 \pm 2.7$ & $13.8 \pm 4.0$ & $13.4 \pm 3.6$ & $12.3 \pm 2.7$ \\
\hline Push-ups (rep) & $6.8 \pm 7.1$ & $9.0 \pm 7.3$ & $13.4 \pm 12.2$ & $10.2 \pm 8.9$ & $9.34 \pm 8.8$ & $10.9 \pm 8.8$ & $16.0 \pm 11.0$ & $16.0 \pm 13.3$ \\
\hline Standing long jump $(\mathrm{cm})$ & $88.6 \pm 15.1$ & $102.3 \pm 21.5$ & $105.8 \pm 20.0$ & $104.7 \pm 38.5$ & $95.9 \pm 18.5$ & $107.0 \pm 22.1$ & $111.1 \pm 23.7$ & $116.3 \pm 38.4$ \\
\hline Handgrip strength (kgf) & $8.2 \pm 1.7$ & $10.2 \pm 2.1$ & $11.6 \pm 2.7$ & $13.4 \pm 2.9$ & $9.9 \pm 2.1$ & $12.1 \pm 2.7$ & $13.5 \pm 3.0$ & $15.7 \pm 3.3$ \\
\hline Shuttle-run (s) & $15.0 \pm 1.6$ & $14.6 \pm 1.6$ & $13.8 \pm 1.3$ & $13.5 \pm 1.7$ & $14.4 \pm 1.4$ & $14.0 \pm 1.6$ & $13.4 \pm 1.4$ & $12.7 \pm 1.4$ \\
\hline
\end{tabular}


Table 2. Tracking coefficients for each GMC test and the motor quotient for boys and girls.

\begin{tabular}{|c|c|c|c|c|c|c|c|}
\hline \multirow[b]{2}{*}{ Tests } & & \multicolumn{2}{|c|}{ Cohen's kappa } & \multirow[b]{2}{*}{ Stability UC (\%) } & \multirow[b]{2}{*}{ Stability LC (\%) } & \multirow[b]{2}{*}{ Instability + (\%) } & \multirow[b]{2}{*}{ Instability - (\%) } \\
\hline & & $\kappa$ & $95 \% \mathrm{Cl}$ & & & & \\
\hline \multirow[t]{2}{*}{ WB } & Girls & 0.28 & $0.22-0.33$ & 7.38 & 12.30 & 4.92 & 4.92 \\
\hline & Boys & 0.27 & $0.21-0.32$ & 6.50 & 10.57 & 6.50 & 6.50 \\
\hline \multirow[t]{2}{*}{ JS } & Girls & 0.32 & $0.26-0.37$ & 12.30 & 12.30 & 2.46 & 2.46 \\
\hline & Boys & 0.35 & $0.29-0.40$ & 13.82 & 12.20 & 3.25 & 1.63 \\
\hline \multirow[t]{2}{*}{$\mathrm{HH}$} & Girls & 0.36 & $0.31-0.41$ & 11.48 & 13.93 & 0.81 & 2.46 \\
\hline & Boys & 0.38 & $0.33-0.43$ & 13.82 & 14.63 & 1.63 & 0.81 \\
\hline \multirow[t]{2}{*}{ MS } & Girls & 0.17 & $0.11-0.22$ & 4.92 & 10.66 & 6.56 & 4.92 \\
\hline & Boys & 0.18 & $0.13-0.24$ & 5.69 & 9.76 & 6.50 & 11.38 \\
\hline \multirow[t]{2}{*}{ MQ } & Girls & 0.44 & $0.39-0.49$ & 14.75 & 18.03 & 0.00 & 1.64 \\
\hline & Boys & 0.45 & $0.39-0.50$ & 14.63 & 19.51 & 1.63 & 0.00 \\
\hline
\end{tabular}

WB: walking backwards; JS: jumping sideways; HH: hoping for height on one foot; MS: moving sideways; MQ GMC: motor quotient of gross motor coordination; UC: upper canal; LC: lower canal; Cl: confidence interval.

$P>0.05 ; \mathrm{HH}: X^{2}=0.58, P>0.05 ; \mathrm{MS}: X^{2}=0.71, P>0.05 ; \mathrm{MQ}:$ $\left.X^{2}=0.90, P>0.05\right)$.

Relative to the identification of stability or instability of the GMC, the percentage of cases remaining in the upper and lower canals is greater than in those showing positive and negative instability in most tests as well as in MQ (Table 2). In girls, the percentage within the upper canal ranged from $4.92 \%$ (MS) to $12.30 \%$ (JS), and within the lower canal from $10.66 \%(\mathrm{MS})$ to $13.93 \%(\mathrm{HH})$. In boys, the percentage within the upper canal ranged from $5.69 \%(\mathrm{MS})$ to $13.83 \%(\mathrm{HH})$, and from $9.76 \%(\mathrm{MS})$ to $14.63 \%(\mathrm{HH})$ within the lower canal. Additionally, girls' positive instability range from $0.81 \%(\mathrm{HH})$ to $6.56 \%$ (MS), while for boys the interval is comprised between $1.63 \%(\mathrm{HH})$ and $6.50 \%$ (WB and $\mathrm{MS}$ ); negative instability range from $2.46 \%$ (JS and $\mathrm{HH}$ ) to $4.92 \%$ (WB and MS) in girls, and from $0.81 \%(\mathrm{HH})$ to $11.38 \%$ (MS) in boys. In both sexes, the percentage of children showing MQ stability within the upper and lower canals is higher than that observed for each of the individual tests, and the instability is negligible (see Table 2 and Figure 2).

Since Cohen's $K$ values did not significantly differ between boys and girls, they were combined into a single group for the retrospective analysis. Table 3 shows the descriptive characteristics and the $P$-values for the differences in anthropometry, physical activity, and health- and performance-related physical fitness variables when moving "back in time", at 6 years of age. Children in the upper canal, i.e., those who consistently are more coordinated, are lighter, present a lower BMI and show lower levels of subcutaneous fat than those peers who are less coordinated. They also show a pattern of better health- and performance-related physical fitness.

\section{Discussion}

The present study uses the concept of developmental canals, as well as Cohen's $k$ statistic, as a novel approach to investigate GMC tracking. Further, we compared the profiles, at 6 years of age, of children that consistently showed stability patterns in high and low GMC levels from 6 to 9 years of age.

Previous GMC tracking studies did not present a clear-cut definition of tracking and relied mostly on auto-correlations. This, of course, poses problems when comparing our results with available data because both are contingent on the way that tracking was conceptualised. Further, we used the idea of
GMC canals widely applied in human physical growth research that monitors individual trends, or groups of individuals, that remain in a particular canal. This approach better reflects the idea of stability of change patterns as well as predictability (Tanner, 1978, 1981).

Our results showed low tracking for all individual GMC tests $(\kappa<0.40)$ and moderate tracking for MQ $(0.44 \leq \kappa \leq 0.45)$. This clearly indicates a strong instability in individual trajectories from 6 to 9 years of age, as well as the difficulty in making individual and/or group predictions about their GMC levels at later ages. This has not been so clearly shown in previous studies because of their strong reliance on auto-correlations. In parallel, the absence of statistically significant differences between girls and boys suggests that both tend to have similar GMC tracking over time.

Since we based our analysis on GMC developmental canals, our findings showed a number of cases of positive and negative instability in each test, but negligible instability when MQ was considered. This is also novel information. Positive instability is highly desirable because it shows that children who started with low GMC levels at 6 years of age exhibited developmental potential to cross canals and achieve a high GMC level at 9 years of age. This was mostly seen in MS among girls and in WB and MS among boys. On the contrary, negative instability showed a decrease in GMC over time, i.e., a change from the upper to the lower canal and was mostly seen in WB (girls) and MS (boys and girls). This information should be used to target children exhibiting these patterns and provide them with remedial programmes within the school system, i.e., in their physical education classes and in supplementary intervention programmes, if needed.

Although no similar analyses are available in GMC research, we found a recent study using the same approach but dealing with the stability of physical fitness across time (Souza et al., 2016). The authors reported similar instability percentages in different physical fitness tests as compared to GMC tests $(1.4-7.2 \%$ for positive instability and $0.9-6.0 \%$ for negative instability). In turn, positive and negative instability was negligible in MQ. This may be due to the fact that the unit or weighted sums, in general, are more reliable and stable than individual tests (Nunnally \& Bernstein, 1994). As an aside, MQ results are more important in clinical practice than within the school setting, because its classification 

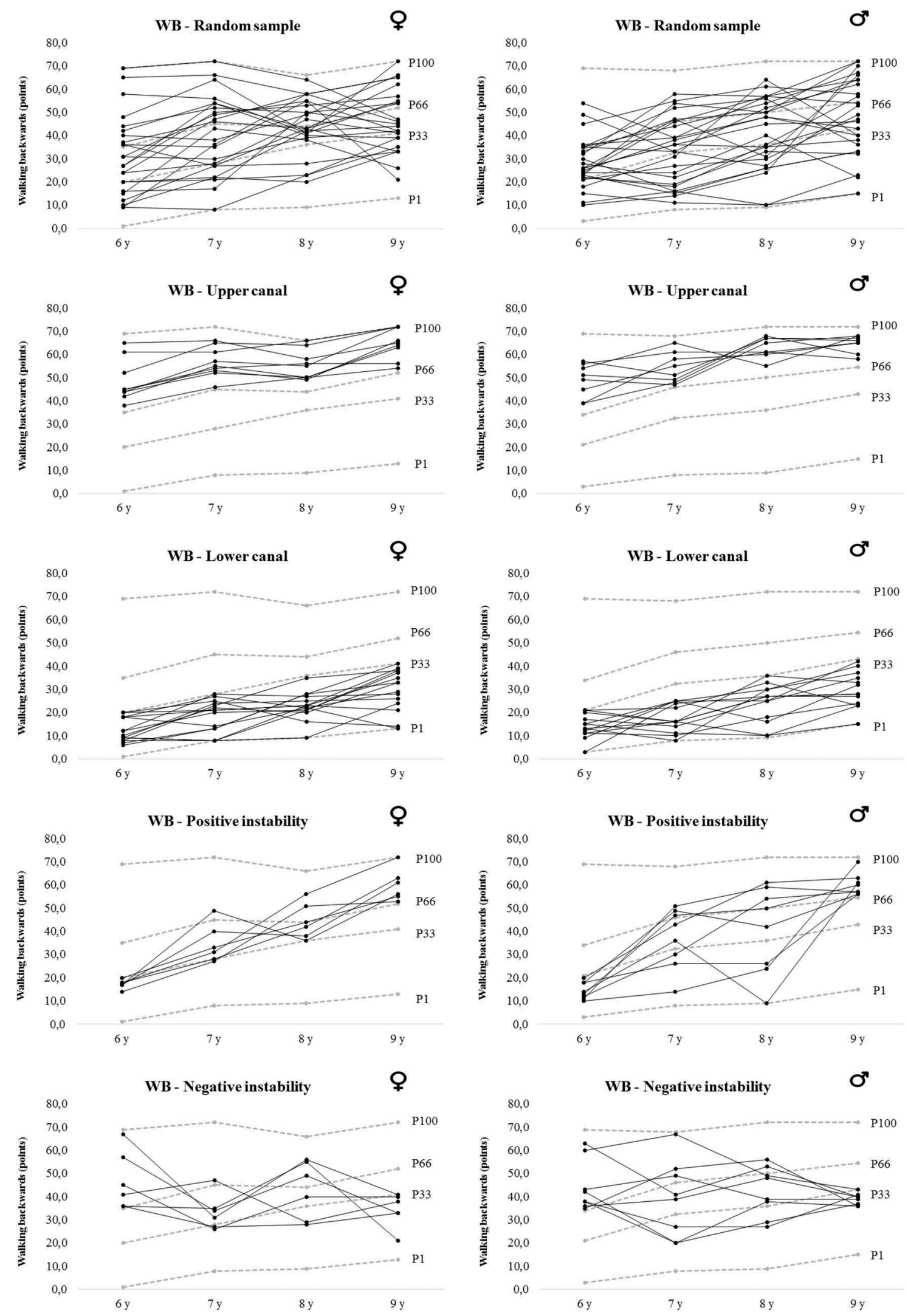

Figure 2. Examples of developmental trajectories in walking backwards (girls and boys) of a random sample (a); participants with stability within the upper canal (b); stability within the lower canal (c); positive instability (d) and negative instability (e).

system allows the identification of children with mild-tosevere motor development impairment requiring specialised clinical intervention. This situation seldom occurs in schools, and is not present in Azorean children.
The identification of stability at the extremes of any distribution is a well-known feature in tracking studies. Our results showed that stability in the lower canal was higher than in the upper canal. This suggests that children classified 
Table 3. Means and standard deviations $( \pm S D)$ for anthropometry, physical activity, and health- and performance-related physical fitness at 6 years of children with stability within the upper and lower canals.

\begin{tabular}{lccrr}
\hline Variables at 6 years & Upper canal & Lower canal & $t$ & $P$-value \\
\hline Anthropometry & & & & \\
Stature (m) & $119.5 \pm 4.7$ & $119.0 \pm 5.8$ & -0.48 & 0.65 \\
Body mass (kg) & $23.8 \pm 3.6$ & $26.7 \pm 6.6$ & 2.37 & 0.02 \\
BMI (kg.m ${ }^{-2}$ ) & $16.6 \pm 1.6$ & $18.6 \pm 3.4$ & 3.39 & $<0.01$ \\
Adiposity (mm) & $12.9 \pm 3.5$ & $23.4 \pm 12.8$ & 4.77 & $<0.01$ \\
Physical activity & & & & \\
Total physical activity & $50.2 \pm 33.0$ & $54.6 \pm 37.0$ & 0.56 & 0.60 \\
Health-related physical fitness & & & & \\
1-mile run/walk (min) & $12.3 \pm 2.3$ & $14.9 \pm 3.0$ & 4.25 & $<0.01$ \\
Push-ups (rep) & $9.1 \pm 10.8$ & $7.6 \pm 7.1$ & -0.77 & 0.44 \\
Curl-ups (rep) & $29.0 \pm 22.7$ & $5.5 \pm 12.5$ & -5.98 & $<0.01$ \\
Trunk lift (cm) & $31.0 \pm 8.3$ & $25.3 \pm 6.3$ & -3.53 & $<0.01$ \\
Performance-related physical fitness & & & & \\
50-yard dash (s) & $10.9 \pm 1.3$ & $13.2 \pm 1.4$ & 7.50 & $<0.01$ \\
Standing long jump (cm) & $104.8 \pm 19.0$ & $81.8 \pm 12.5$ & -6.57 & $<0.01$ \\
Handgrip strength (kgf) & $10.3 \pm 2.1$ & $8.8 \pm 2.1$ & -3.03 & $<0.01$ \\
Shuttle-run (s) & $13.6 \pm 1.0$ & $15.7 \pm 1.8$ & 6.19 & $<0.01$ \\
\hline
\end{tabular}

with low GMC levels tend to maintain their relative position rather than those having higher GMC. This is important information, because of potential adverse effects of low GMC on physical, cognitive and psychological health (Chaves et al., 2016; Skinner \& Piek, 2001). Although our study is not concerned with identifying children with developmental coordination disorder, it is plausible to speculate that the moderate kappa may suggest that stability in the lower canal of some children could be linked to this condition.

When moving "back in time", we compared anthropometric, physical activity, and health- and performancerelated physical fitness data at 6 years of age of those children who persistently stayed in the upper and lower GMC canals. Those who consistently were more coordinated had healthier profiles - were lighter, had lower BMI and subcutaneous fat, and had higher health- and performancerelated physical fitness levels. The same pattern of results occurred at 9 years of age for all variables (data not shown). There is evidence, mostly from cross-sectional studies, that a positive relationship between GMC and physical fitness exists (Cattuzzo et al., 2016; Souza et al., 2014), as well as for a negative association between GMC and weight status and/or adiposity (Cattuzzo et al., 2016; Lopes et al., 2012). GMC and physical fitness tests involve different degrees of skill and movement control of the entire body, or body segments; further, each of the KTK tests has a relatively complex motor structure that differs from the physical fitness tests. It is thus possible that children who are constantly more coordinated may have better inter- and intraneuromuscular control allowing them to generate and apply greater force, as well as effectively produce more skilful motor patterns (Stodden, Gao, Goodway, \& Langendorfer, 2014; Stodden et al., 2008). Additionally, increases in body mass may result in movement inefficiencies, particularly in overweight or obese children (D'Hondt et al., 2011; Robinson et al., 2015).

We did not find, at 6 years of age, any statistically significant difference in physical activity levels of children consistently placed in the upper and lower GMC canals. This may suggest that high and low GMC levels do not necessarily require distinct physical activity levels (Holfelder \& Schott, 2014). Yet, a different result was seen at 9 years of age when more coordinated children had higher physical activity levels (data not shown). The emergence of physical activity differences in older children is consistent with the "activity deficit hypothesis" (Cairney, Hay, Veldhuizen, Missiuna, \& Faught, 2010; Wall, 2004). As suggested by Wall (2004), motor skills' demands to participate in physical activities increase with age, and children who consistently remained in the lower canal may find it difficult to actively engage in them. This participation gap will most probably increase over time, especially in competitive and culturally configured physical activities.

This study is not without limitations. The first limitation relates to using a questionnaire to estimate physical activity because it is well known that children have difficulties recalling and quantifying their activities. Financial reasons limited our physical activity assessments to a questionnaire. However, all children were directly interviewed in standardised conditions, and this questionnaire has shown to be reliable in other Portuguese studies (Chaves et al., 2015; Lopes et al., 2001). Second, the sample size limits the generalisation of results to other Portuguese children living on the mainland and in the Madeira islands. Third, no interteacher reliability analysis was done. Since the rating of GMC is very simple and straightforward, we thought that teachers' variance would have little "impact" on the reliability of the children's KTK performance. Yet, this study has also several strengths: (1) the data has broad representation of Azorean school children; (2) the number of time points is larger than most available studies; (3) the broad array of measures, namely physical fitness, body fat and physical activity, together with GMC is not seen in other research; (4) the use of a novel approach to investigate GMC tracking and (5) the profiling of distinct health-related characteristics that consistently differentiate children according to their GMC across time.

In conclusion, our results show a strong instability of individual GMC trajectories across childhood, and a better health profile at 6-year-old children who are consistently better coordinated. This clearly illustrates the importance of GMC and suggests that GMC, by itself, can also be considered as a proxy health indicator of children. This information is useful to teachers of physical education, parents and coaches in order to identify children with distinct GMC trajectories over time and to develop specific intervention programmes.

\section{Disclosure statement}

No potential conflict of interest was reported by the authors.

\section{References}

Ahnert, J., Schneider, W., \& Bös, K. (2009). Developmental changes and individual stability of motor abilities from the preschool period to young adulthood. In W. Schneider \& M. Bullock (Eds.), Human development from early childhood to early adulthood: Evidence from the Munich longitudinal study on the genesis of individual competencies (LOGIC) (pp. 35-62). Mahwah: Erlbaum. 
American Alliance for Health, Physical Education, Recreation and Dance. (1980). Health related physical fitness manual. Washington: AAHPERD.

Antunes, A. M., Maia, J. A., Gouveia, É. R., Thomis, M. A., Lefevre, J. A., Teixeira, A. Q., \& Freitas, D. L. (2016). Change, stability and prediction of gross motor co-ordination in Portuguese children. Annals of Human Biology, 43(3), 201-211. doi:10.3109/03014460.2015.1058419

Antunes, A. M, Maia, J. A, Stasinopoulos, M. D, Gouveia, É. R, Thomis, M. A, Lefevre, J. A, \& Freitas, D. L. (2015). Gross motor coordination and weight status of portuguese children aged 6-14 years. American Journal Of Human Biology, 27(5), 681-689. doi: 10.1002/ajhb.22715

Berenson, G. S., Foster, T. A., Frank, G. C., Frerichs, R. R., Srinivasan, S. R., Voors, A. W., \& Webber, L. S. (1978). Cardiovascular disease risk factor variables at the preschool age. Circulation, 57(3), 603-612. doi:10.1161/01.CIR.57.3.603

Cairney, J., Hay, J. A., Veldhuizen, S., Missiuna, C., \& Faught, B. E. (2010). Developmental coordination disorder, sex, and activity deficit over time: A longitudinal analysis of participation trajectories in children with and without coordination difficulties. Developmental Medicine and Child Neurology, 52(3), e67-e72. doi:10.1111/j.1469-8749.2009.03520.x

Cattuzzo, M. T., Henrique, R. S., Ré, A. H., Oliveira, I. S., Melo, B. M., Moura, M. S., ... Stodden, D. (2016). Motor competence and health related physical fitness in youth: A systematic review. Journal of Science and Medicine in Sport, 19(2), 123-129. doi:10.1016/j.jsams.2014.12.004

Chaves, R., Baxter-Jones, A., Gomes, T., Souza, M., Pereira, S., \& Maia, J. (2015). Effects of individual and school-level characteristics on a child's gross motor coordination development. International Journal of Environmental Research and Public Health, 12(8), 8883-8896. doi:10.3390/ijerph120808883

Chaves, R., Bustamante, A., Nevill, A., Freitas, D., Tani, G., Katzmarzyk, P. T., \& Maia, J. A. (2016). Developmental and physical-fitness associations with gross motor coordination problems in Peruvian children. Research in Developmental Disabilities, 53-54, 107-114. doi:10.1016/j. ridd.2016.01.003

Clarke, W. R., Schrott, H. G., Leaverton, P. E., Connor, W. E., \& Lauer, R. M. (1978). Tracking of blood lipids and blood pressures in school age children: The Muscatine study. Circulation, 58(4), 626-634. doi:10.1161/01.CIR.58.4.626

Cohen, J. (1960). A coefficient of agreement for nominal scales. Educational and Psychological Measurement, 20(1), 37-46. doi:10.1177/ 001316446002000104

Cole, T. J., Bellizzi, M. C., Flegal, K. M., \& Dietz, W. H. (2000). Establishing a standard definition for child overweight and obesity worldwide: International survey. Bmj, 320(7244), 1240-1246. doi:10.1136/ bmj.320.7244.1240

D'Hondt, E., Deforche, B., Vaeyens, R., Vandorpe, B., Vandendriessche, J., Pion, J., ... Lenoir, M. (2011). Gross motor coordination in relation to weight status and age in 5-to 12-year-old boys and girls: A crosssectional study. International Journal of Pediatric Obesity, 6(2-2), 556564. doi:10.3109/17477166.2010.500388

Deus, R. K., Bustamante, A. V., Lopes, V. P., Seabra, A., Silva, R. G., \& Maia, J. A. (2008). Coordenação motora: Um estudo de tracking em crianças dos 6 aos 10 anos da Região Autónoma dos Açores, Portugal. Revista Brasileira De Cineantropometria E Desempenho Humano, 10(3), 215222. doi:10.5007/1980-0037.2008v10n3p215

Eisenmann, J. C., Milburn, N., Jacobsen, L., \& Moore, S. J. (2002). Reliability and convergent validity of the Godin leisure-time exercise questionnaire in rural 5th-grade school-children. Journal of Human Movement Studies, 43(2), 135-149.

Fransen, J., Deprez, D., Pion, J., Tallir, I., D'Hondt, E., Vaeyens, R., ... Philippaerts, R. (2014). Changes in physical fitness and sports participation among children with different levels of motor competence: A 2year longitudinal study. Pediatric Exercise Science, 26(1), 11-21. doi:10.1123/pes.2013-0005

Godin, G., \& Shephard, R. J. (1985). A simple method to assess exercise behavior in the community. Canadian Journal of Applied Sport Sciences, 10(3), 141-146.

Holfelder, B., \& Schott, N. (2014). Relationship of fundamental movement skills and physical activity in children and adolescents: A systematic review. Psychology of Sport and Exercise, 15(4), 382-391. doi:10.1016/j. psychsport.2014.03.005

IBM. (2015). IBM SPSS statistics for windows, version 23.0. Armonk, NY: IBM.
Kiphard, E. J., \& Schilling, F. (1974). Körperkoordinationstest für Kinder. Weinheim: Beltz Test GmbH.

Kowalski, C. J., \& Schneiderman, E. D. (1992). Tracking: Concepts, methods and tools. International Journal of Anthropology, 7(4), 33-50. doi:10.1007/BF02447868

Landis, J., \& Koch, G. (1977). The measurement of observer agreement for categorical data. Biometrics, 33(1), 159-174. doi:10.2307/2529310

Lohman, T., Roche, A., \& Martorell, R. (1988). Anthropometric standardization reference manual. Champaign: Human Kinetics Books.

Lopes, V. P., Monteiro, A. M., Barbosa, T. M., Magalhães, P. M., \& Maia, J. A. (2001). Actividade física habitual em crianças pré-púberes. Diferenças entre rapazes e raparigas. Revista Portuguesa De Ciências Do Desporto, 1 (3), 53-60. doi:10.5628/rpcd.01.03.53

Lopes, V. P., Rodrigues, L., Maia, J. A., \& Malina, R. M. (2011). Motor coordination as predictor of physical activity in childhood. Scandinavian Journal of Medicine \& Science in Sports, 21(5), 663-669. doi:10.1111/j.1600-0838.2009.01027.x

Lopes, V. P., Stodden, D. F., Bianchi, M. M., Maia, J. A., \& Rodrigues, L. P. (2012). Correlation between BMI and motor coordination in children. Journal of Science and Medicine in Sport, 15(1), 38-43. doi:10.1016/j. jsams.2011.07.005

Maia, J. A., Lefevre, J., Claessens, A., Renson, R., Vanreusel, B., \& Beunen, G. (2001). Tracking of physical fitness during adolescence: A panel study in boys. Medicine \& Science in Sports \& Exercise, 33(5), 765-771. doi:10.1097/00005768-200105000-00014

Malina, R. M. (2001). Physical activity and fitness: Pathways from childhood to adulthood. American Journal of Human Biology, 13(2), 162-172. doi:10.1002/(ISSN)1520-6300

Nunnally, J. C., \& Bernstein, I. H. (1994). Psychometric theory (3nd ed.). New York: McGraw-Hill.

Robinson, L. E., Stodden, D. F., Barnett, L. M., Lopes, V. P., Logan, S. W. Rodrigues, L. P., \& D'Hondt, E. (2015). Motor competence and its effect on positive developmental trajectories of health. Sports Medicine, 45(9), 1273-1284. doi:10.1007/s40279-015-0351-6

Rodrigues, L. P, Stodden, D. F, \& Lopes, V. P. (2016). Developmental pathways of change in fitness and motor competence are related to overweight and obesity status at the end of primary school. Journal of Science And Medicine In Sport, 19(1), 87-92. doi: 10.1016/j. jsams.2015.01.002

Scerpella, T. A., Tuladhar, P. R., \& Kanaley, J. A. (2002). Validation of the GodinShephard questionnaire in prepubertal girls. Medicine \& Science in Sports \& Exercise, 34(5), 845-850. doi:10.1097/00005768-200205000-00018

Schneiderman, E. D., Willis, S. M., Kowalski, C. J., \& Ten Have, T. R. (1992). PC program for comparing tracking indices in several independent groups. American Journal of Human Biology, 4(3), 399-401. doi:10.1002/(ISSN)1520-6300

Skinner, R. A., \& Piek, J. P. (2001). Psychosocial implications of poor motor coordination in children and adolescents. Human Movement Science, 20 (1), 73-94. doi:10.1016/S0167-9457(01)00029-X

Souza, M. C., Chaves, R. N., Lopes, V. P., Malina, R. M., Garganta, R., Seabra, A., \& Maia, J. A. (2014). Motor coordination, activity, and fitness at 6 years of age relative to activity and fitness at 10 years of age. Journal of Physical Activity \& Health, 11(6), 1239-1247. doi:10.1123/jpah.2012-0137

Souza, M. C., Eisenmann, J., Chaves, R., Santos, D., Pereira, S., Forjaz, C., \& Maia, J. A. (2016). A methodological approach to short-term tracking of youth physical fitness: The Oporto Growth, Health and Performance Study. Journal of Sports Sciences. doi:10.1080/ 02640414.2016.1142105

Stodden, D. F., Gao, Z., Goodway, J. D., \& Langendorfer, S. J. (2014). Dynamic relationships between motor skill competence and healthrelated fitness in youth. Pediatric Exercise Science, 26(3), 231-241. doi:10.1123/pes.2013-0027

Stodden, D. F., Goodway, J. D., Langendorfer, S. J., Roberton, M. A., Rudisill, M. E., Garcia, C., \& Garcia, L. E. (2008). A developmental perspective on the role of motor skill competence in physical activity: An emergent relationship. Quest, 60(2), 290-306. doi:10.1080/00336297.2008.10483582

Tanner, J. M. (1978). Foetus into man: Physical growth from conception to maturity. Cambridge: Harvard University Press. 
Tanner, J. M. (1981). A history of the study of human growth. Cambridge: Cambridge University Press.

Twisk, J. W. (2003). Applied longitudinal data analysis for epidemiology: A practical guide. London: Cambridge University Press.

Twisk, J. W., Kemper, H. C., \& Mellenbergh, G. J. (1994). Mathematical and analytical aspects of tracking. Epidemiologic Reviews, 16(2), 165-183. doi:10.1093/oxfordjournals.epirev.a036149

Waddington, C. H. (1942). Canalization of development and the inheritance of acquired characters. Nature, 150(3811), 563-565. doi:10.1038/150563a0

Waddington, C. H. (1957). Strategy of the genes: A discussion of some aspects of theoretical biology. London: Allen and Unwin.
Wall, A. E. (2004). The developmental skill-learning gap hypothesis: Implications for children with movement difficulties. Adapted Physical Activity Quarterly, 21(3), 197-218. doi:10.1123/apaq.21.3.197

Ware, J. H., \& Wu, M. C. (1981). Tracking: Prediction of future values from serial measurements. Biometrics, 37(3), 427-437. doi:10.2307/2530556

Welk, G. J., \& Meredith, M. D. (2008). Fitnessgram/Activitygram reference guide. Dallas: The Cooper Institute.

Willimczik, K. (1980). Development of motor control capability (body coordination) of 6-to 10-year-old children: Results of a longitudinal study. In M. Ostyn, G. Beunen, \& J. Simons (Eds.), Kinanthropometry II (pp. 328-346). Baltimore: University Park Press. 